\title{
UWB Bandpass Filter with Dual Notched Bands Using T-Shaped Resonator and L-Shaped Defected Microstrip Structure
}

\author{
Xuemei Zheng ${ }^{1,2}$, Yuwen Pan $^{3}$ and Tao Jiang ${ }^{1, *}$ \\ 1 College of Information and Communication Engineering, Harbin Engineering University, Harbin 150001, \\ China; zhengxuemei@hrbeu.edu.cn \\ 2 College of Information Engineering, Northeast Electric Power University, Jilin 132012, China \\ 3 Research and Development Department, Sainty-Tech Communications Limited, Nanjing 211100, China; \\ peter.pan@sainty-tech.com \\ * Correspondence: jiangtao@hrbeu.edu.cn; Tel.: +86-451-8251-9808
}

Received: 12 April 2018; Accepted: 29 May 2018; Published: 1 June 2018

\begin{abstract}
In this paper, an ultra-wideband (UWB) bandpass filter (BPF) with dual notched bands using a T-shaped resonator and L-shaped defected microstrip structure (DMS) is proposed and fabricated. First, the principle of generating notched bands by using a T-shaped resonator and L-shaped defected microstrip structure to determine the size parameters of the structure is analyzed. High frequency structure simulator (HFSS) software is used to analyze the performance of the filter, and advanced design system (ADS) is used to extract the equivalent circuit model parameters. The two simulation results are consistent, which further verifies the correctness of the circuit model. Finally, the filter is fabricated and measured. The measured results are in good agreement with simulated results, demonstrating good insertion loss and return loss. The proposed filter has dual independently controllable notched bands which are implemented by coupling the T-shaped resonator to the transmission line and by etching the L-shaped defected microstrip structure respectively. The proposed filter can suppress dispensable bands at $3.5 \mathrm{GHz}$ and $7.5 \mathrm{GHz}$ in WiMAX band and X-band to improve the performance of the ultra-wideband communication system. By adjusting the parameters of the T-shaped resonator and L-shaped defected microstrip structure, the UWB bandpass filter with dual notched bands working at WiMAX band and X-band can be designed and applied to the wireless communication system.
\end{abstract}

Keywords: microstrip filters; defected microstrip structure; microstrip circuits; bandpass filter

\section{Introduction}

Ultra-wideband (UWB) communication systems are widely used in wireless communication because of low cost and high data rate. The ultra-wideband (3.1-10.6 GHz) frequency spectrum was announced by the Federal Communications Commission in 2002 [1] for unlicensed indoor and hand-held commercial applications. ultra-wideband filters, as one of the key components of the radio frequency front-end, directly affect the quality of communication systems. Some other existing narrowband services already occupy frequencies in the ultra-wideband band, such as WiMAX in some Asian and European countries (3.4-3.6 GHz), and X-band satellite communication services frequency band $(7.25-8.395 \mathrm{GHz})$. Therefore, it is necessary to design a ultra-wideband bandpass filter with notched bands. In order to realize the miniaturization and narrow-band notch of microwave integrated circuits, ultra-wideband filters require better frequency selection performance, a more compact structure, and seamless integration. 
A number of techniques to design ultra-wideband bandpass filters with notched bands have been studied [2-16]. The notch bands are generated by introducing a resonance unit, such as a stepped impedance resonator (SIR) [2,3] and multi-mode resonator (MMR) [4-9]. The disadvantage of adopting stepped impedance resonator or multi-mode resonator is that the size of the notch filter is too large and the transmission zero cannot be flexibly adjusted. The stop-band function is achieved by introducing defect ground structure (DGS) [10,11] and defect microstrip structure (DMS) [12,13]. Defect ground structure can effectively reduce the size of the filter, but it is difficult to obtain good broadband and sharp skirt selectivity. In addition, there is leakage of the floor. The microstrip filter based on defect microstrip structure can solve the floor leakage problem. The coplanar waveguide (CPW) [14-16] is used to achieve notch characteristics. The coupling between the microstrip line and the coplanar waveguide is strong and the filter structure is compact, but the stop band characteristic is generally not good. Novel dual-band bandpass filters are implemented for $3.5 \mathrm{GHz}$ and $5.8 \mathrm{GHz}$ in [17], and the pass band of the proposed filter covers $2.4 \mathrm{GHz}, 2.5 \mathrm{GHz}$, and $3.5 \mathrm{GHz}$ in [18]. In order to remove interference from WiMAX and satellite communication bands, a dual notched ultra-wideband bandpass filter is proposed in this paper.

A dual notched ultra-wideband bandpass filter using a T-shaped resonator and L-shaped defect microstrip structure is proposed and fabricated. The first and second notched band functions are respectively implemented by coupling the T-Shaped resonator to the transmission line and etching the L-shaped defect microstrip structure on the bandpass filter. In the second section, we will discuss the design of the ultra-wideband filter with dual notched bands and study the frequency rejection function based on a T-shaped resonator and L-shaped defect microstrip structure. In the third section, a dual bandpass filter with notched bands is fabricated and measured, with the measured results in good agreement with simulated results, demonstrating good insertion loss and return loss. By adjusting the parameters of the T-shaped resonator and L-shaped defect microstrip structure, the ultra-wideband bandpass filter with dual notched bands working at WiMAX band and X-band can be designed and applied to the wireless communication system.

\section{Filter Design}

The proposed dual notched ultra-wideband bandpass filter using a T-shaped resonator and L-shaped defect microstrip structure is designed on a bandpass filter in the literature [5]. The structure of a ultra-wideband bandpass filter without a T-shaped resonator and L-shaped defect microstrip structure is shown in Figure 1a. Figure $1 \mathrm{~b}$ lays out the simulation results of a basic ultra-wideband bandpass filter by using high frequency structure simulator (HFSS) software (ANSYS, Inc., Canonsburg, PA, USA). To satisfy the requirements for ultra-wideband performance and improve edge steepness of the passband, four short-circuited stubs (length of $\lambda / 4$ ) are used. Figure $1 b$ indicates that the bandwidth of the bandpass filter is from 2.632 to $10.623 \mathrm{GHz}$ and the fractional bandwidths (FBW) is $123.9 \%$. The insertion loss of the ultra-wideband bandpass filter is less than $0.8 \mathrm{~dB}$, while the simulated return loss is greater than $16 \mathrm{~dB}$ within the passband.

Figure 2 shows the design process of the dual notched bands filter. The basic filter can form the first notched band by using the T-shaped resonator and the second notched band by using the L-shaped defect microstrip structure. Figure 3a,b shows the circuit configuration of the proposed filter and its $S$ parameters, which are calculated by HFSS. The proposed filter achieves dual notched bands, whose center frequencies are at the 3.5 and $7.5 \mathrm{GHz}$, respectively. On notched frequencies, the corresponding reflection coefficient is $-28.6 \mathrm{~dB}$ and $-25.1 \mathrm{~dB}$ with a the fractional bandwidths (FBW) of $15.76 \%$ and $4.96 \%$, respectively. 


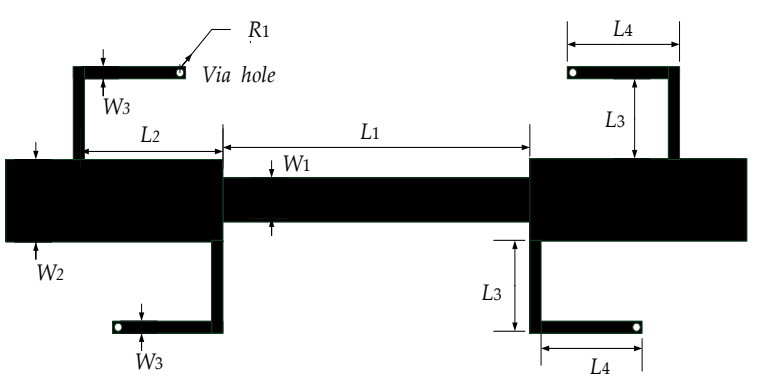

(a)

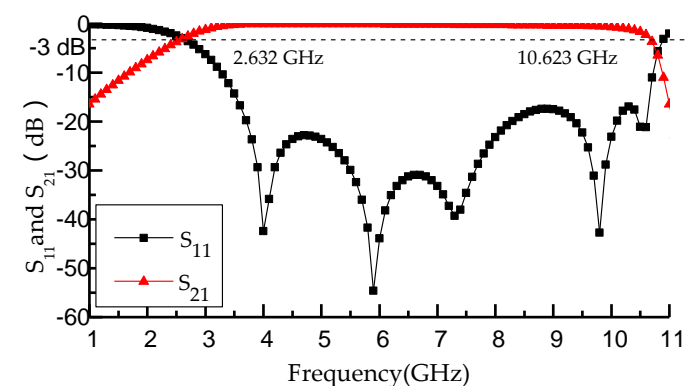

(b)

Figure 1. (a) Structure of ultra-wideband bandpass filter without T-shaped resonator and L-shaped defect microstrip structure; (b) simulation results of the ultra-wideband bandpass filter without T-shaped resonator and L-shaped defect microstrip structure.

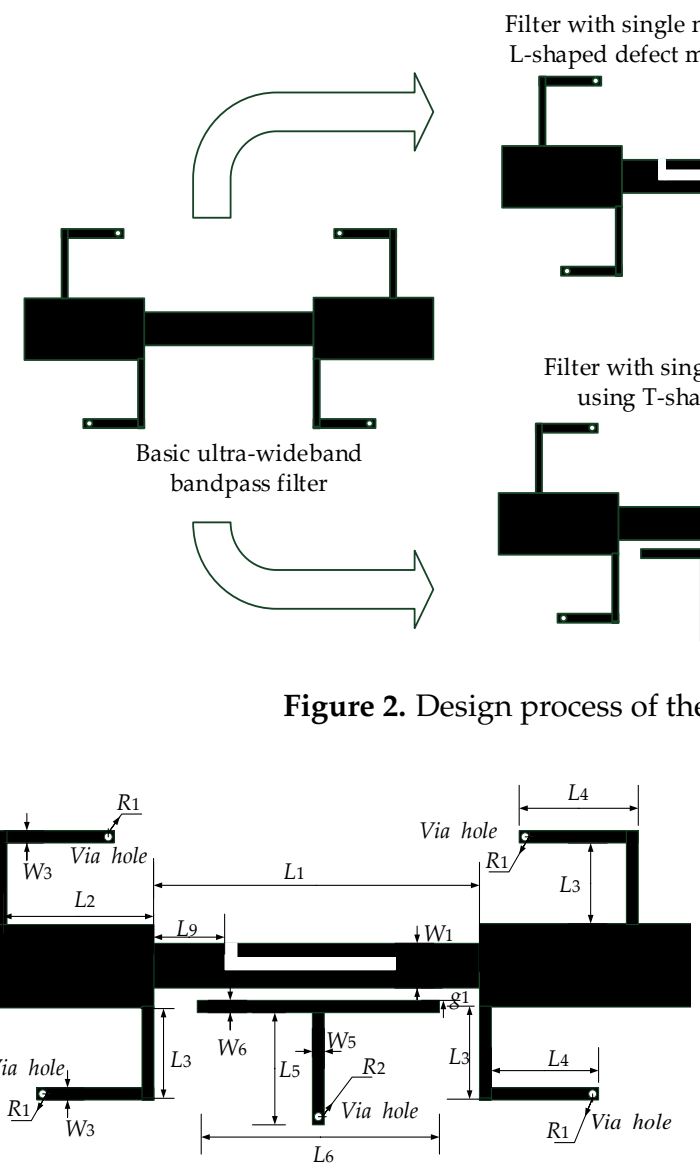

(a)

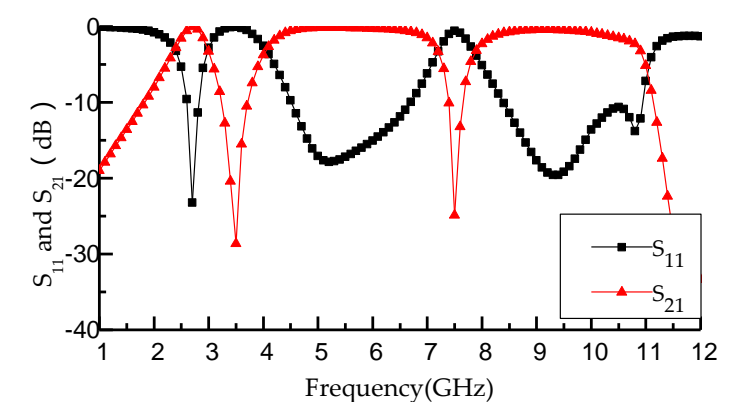

(b)

Figure 3. (a) The circuit of the proposed filter; (b) simulation results of the proposed filter.

Figure 4 shows the structure of the T-shaped resonator and further analyzes its even-mode and odd-mode equivalent circuit. By using odd-mode and even-mode analysis method [6], the input impedance of even-mode and odd-mode can be expressed as the Equations (1) and (2), where $\theta_{1}$ and $\theta_{2}$ are the electrical length of the open-circuited stub and the short-circuited stub, respectively.

$$
\begin{gathered}
Z_{\text {ine }}=j Z_{6} \frac{Z_{6} \tan \theta_{6}+2 Z_{5} \tan \theta_{5}}{Z_{6}-2 Z_{5} \tan \theta_{6} \tan \theta_{5}} \\
Z_{\text {ino }}=j Z_{6} \tan \theta_{6}
\end{gathered}
$$


$\theta_{6}$ is defined as the electrical length of the open-circuited stub, $\theta_{5}$ is defined as the electrical length of the short-circuited stub, which can be expressed as:

$$
\theta_{5}=\beta L_{6}, \quad \theta_{6}=\beta L_{6} / 2
$$

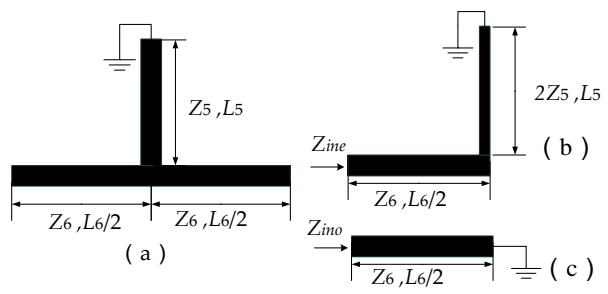

Figure 4. (a) The structure of T-shaped resonator; (b) even-mode equivalent circuit; (c) odd-mode equivalent circuit $\left(Z_{5}\right.$ and $Z_{6}$ are the characteristic impedance. $L_{5}$ and $L_{6} / 2$ are length of the open-circuited stub and the short-circuited stub).

The even-mode resonant frequency $f_{\text {even }}$ and odd-mode resonant frequency $f_{\text {odd }}$ can be expressed as shown in Equations (4) and (5). If the two signals are in the same phase, they are stacked together to form a pass band. However, in this frequency range, the two signals' phase is opposite, and the stop band is formed. In order to further reduce the difficulty of design, the parameter is made $L_{6}=2 L_{5}$. In this way, the resonant frequency of odd mode and even mode are only related to $L_{6}$, and the first resonance frequency is adjusted by adjusting $L_{6}$.

$$
\begin{aligned}
f_{\text {even }}=\frac{c}{4\left(L_{6} / 2+L_{5}\right) \sqrt{\varepsilon_{\text {eff }}}} & =\frac{c}{4\left(L_{6} / 2+L_{6} / 2\right) \sqrt{\varepsilon_{\text {eff }}}}=\frac{c}{4 L_{6} \sqrt{\varepsilon_{\text {eff }}}} \\
f_{\text {odd }} & =\frac{c}{2 L_{6} \sqrt{\varepsilon_{\text {eff }}}}
\end{aligned}
$$

Figure 5a illustrates the structure of the L-shaped defect microstrip structure, whose width is $\mathrm{W}_{7}$ and length is the sum of $L_{7}$ and $L_{8}$. The notch band characteristics are formed by using defect microstrip structure similar to using defect ground structure [19], and the resonant unit cell are modeled by L-shaped defect microstrip structure and the T-shaped resonator, i.e., Figure $4 \mathrm{~b}$, only considers the first and second resonant modes, which shows the equivalent lumped circuit of the resonant elements composed of the T-shaped resonator and L-shaped defect microstrip structure.

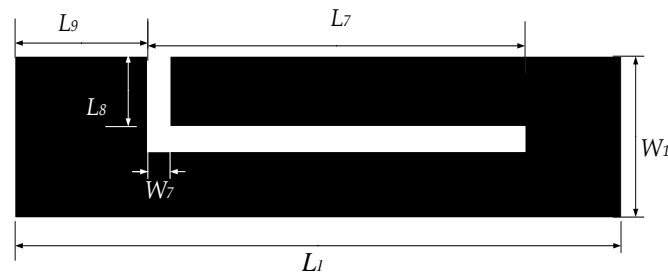

(a)

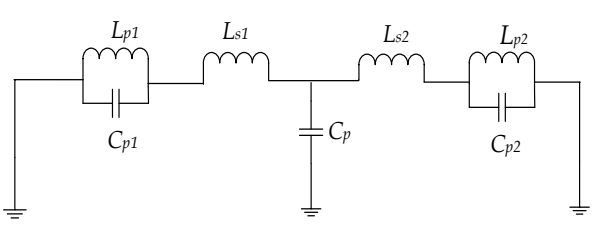

(b)

Figure 5. (a) The element structure of L-shaped defect microstrip structure; (b) the equivalent lumped circuit of T-shaped resonator and L-shaped defect microstrip structure.

According to the theory of transmission line, each resonant element can be equivalent to a simple LC parallel resonant circuit with a characteristic that is similar to the first order Butterworth low-pass filter. Therefore, the equivalent circuit model Equations (6)-(10) of the two resonant elements composed of the T-shaped resonator and the L-shaped defect microstrip structure can be deduced from the Butterworth low-pass filter circuit model, where $f_{T}$ means a transit frequency, while $f_{01}$ and $f_{02}$ describe the lower and the higher resonant frequencies. The 3-dB bandwidth at $f_{01}$ and $f_{02}$ are 
denoted by $\Delta_{3 \mathrm{~dB}_{-} f_{01}}$ and $\Delta_{3 \mathrm{~dB}_{-} f_{02}}$. The imaginary parts of three $Z$ parameters at $f_{T}$ are $X_{11}, X_{22}$ and $X_{21}$. The following equivalent formulas regarding resonant elements composed of the T-shaped resonator and L-shaped defect microstrip structure can be derived from Reference [3]. The equivalent equations of resonant elements composed of the T-shaped resonator and L-shaped defect microstrip structure are shown in Reference [19].

$$
\begin{gathered}
C_{p i}=\frac{1}{4 \pi Z_{0} \Delta_{3 \mathrm{~dB}_{-} f_{0 i}}} \text { for } i=1,2 \\
L_{p i}=\frac{1}{\left(2 \pi f_{0 i}\right)^{2} C_{p s i}} \text { for } i=1,2 \\
C_{p}=\frac{1}{2 \pi f_{T} X_{21}} \\
L_{s i}=\frac{X_{i i}-X_{21}}{2 \pi f_{T}}+\frac{L_{p i}}{\left(f_{T} / f_{0 i}\right)^{2}-1} \text { for } i=1,2
\end{gathered}
$$

Defect microstrip structure has the same slow wave characteristics as DGS, so the resonant frequency can be derived from the method of DGS [20]. The L-shaped defect microstrip structure can be regarded as a half guided wavelength crooked slot line resonator. Therefore, the resonant frequency $f$ may be achieved as:

$$
f=\frac{c}{2 L \sqrt{\varepsilon_{\text {slot }}}}
$$

where $c$ is the free-space speed of light, $L=L_{7}+L_{8}$ the total length of the L-shaped defect microstrip structure, and $\varepsilon_{\text {slot }}$ is the effective dielectric constant of the slot acquired by the closed-form equations in Reference [21]. The circuit parameters extracted from the ADS is shown in Table 1. Figure 6 shows the comparison of HFSS and ADS simulation results regarding the equivalent equation of resonant elements composed with the T-shaped resonator and L-shaped defect microstrip structure. It can be seen from Figure 6 that the ADS simulation results and the HFSS simulation results have the same resonant frequencies at $3.5 \mathrm{GHz}$ and $7.5 \mathrm{GHz}$ with the same insertion loss $28.6 \mathrm{~dB}$, which proves the validity and correctness of the equivalent circuit. Figure 7 shows the photograph of the fabricated filter which selects RT/Duorid5880 (Rogers Corporation, Chandler, AZ, USA) as a substrate with the size of $32 \mathrm{~mm} \times 10 \mathrm{~mm} \times 1 \mathrm{~mm}$.

Table 1. The circuit parameters in Figure $5 b$ extracted from the advanced design system (ADS).

\begin{tabular}{cc}
\hline$C(\mathrm{pF})$ & $\boldsymbol{L}(\mathbf{n H})$ \\
\hline$C_{\mathrm{p} 1}=2.415$ & $L_{\mathrm{p} 1}=0.85$ \\
$C_{\mathrm{p}}=2.489$ & $L_{\mathrm{s} 1}=0.18$ \\
$C_{\mathrm{p} 2}=0.1216$ & $L_{\mathrm{s} 2}=-0.105$ \\
- & $L_{\mathrm{p} 2}=0.47$ \\
\hline
\end{tabular}

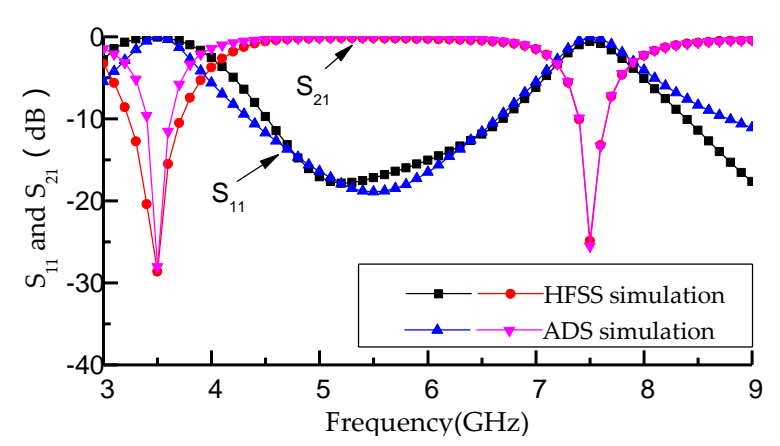

Figure 6. The comparison of simulation results by using high frequency structure simulator (HFSS) and advanced design system (ADS). 


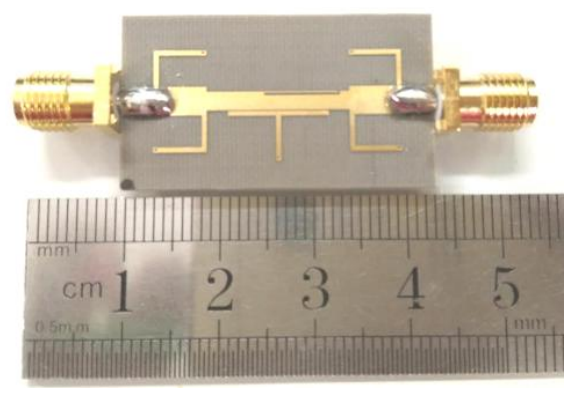

Figure 7. The photograph of the fabricated filter.

\section{Results and Discussion}

In this paper, the T-shaped resonator is coupled to the basic ultra-wideband filter and the L-shaped defect microstrip structure is realized by etching an asymmetric L slot line whose width is $W_{7}$. The T-shaped resonator is comprised of short-stub $\left(L_{5}, W_{5}\right)$ and open-stub $\left(L_{6}, W_{6}\right)$ with equal length and width $\left(L_{5}=L_{6}, W_{5}=W_{6}\right)$ so that the impedance ratio $\left(K=Z_{2} / Z_{1}\right)$ only depends on their electrical length. The final size of the filter is optimized by using HFSS with $0.1 \mathrm{GHz}$ sweep step.

Optimized design parameters of the proposed ultra-wideband filter is given in Table 2. The simulated and fabricated results proved that the first notched band is adjustable by the parameters $\left(g_{1}, L_{6}\right.$ and $\left.W_{6}\right)$ of the T-shaped resonator, while the second notched band is controlled by the parameters $\left(L_{7}, L_{8}\right.$ and $\left.W_{7}\right)$ of the L-shaped defect microstrip structure.

Table 2. Optimized design parameters of the proposed ultra-wideband filter (The units are mm).

\begin{tabular}{cccccc}
\hline Length & Length & Width & Width & Radius & Gap Length \\
\hline$L_{1}=15$ & $L_{5}=5.3$ & $W_{1}=1.95$ & $W_{5}=0.5$ & $R_{1}=0.15$ & $g_{1}=0.1$ \\
$L_{2}=5$ & $L_{6}=10.6$ & $W_{2}=3$ & $W_{6}=0.3$ & $R_{2}=0.15$ & - \\
$L_{3}=4$ & $L_{7}=9$ & $W_{3}=0.3$ & $W_{7}=0.1$ & - & - \\
$L_{3}=4$ & $L_{8}=0.1$ & $W_{4}=1.4$ & $W_{8}=0.3$ & - & - \\
\hline
\end{tabular}

The simulation results of the T-shaped resonator and L-shaped defect microstrip structure is given in Tables 3 and 4. It can be concluded that the lower frequency notched band with a 3-dB bandwidth of $1.07 \mathrm{GHz}$ was generated by the T-shaped resonator, and the higher frequency notched band with a 3-dB bandwidth of $0.61 \mathrm{GHz}$ was realized by etching the L-shaped defect microstrip structure. It can be seen that the first notch band has a fractional bandwidths (FBW) of about $15.47 \%$ and the second notch band has a FBW of about $8.76 \%$. Moreover, the measured results show that the dual notched bands are observed at 3.5 and $7.5 \mathrm{GHz}$ with the rejection level of $25.2 \mathrm{~dB}$ and $17.3 \mathrm{~dB}$, with a fractional bandwidths (FBW) of $15.91 \%$ and $9.63 \%$.

Table 3. Simulation results of the dual notched bands.

\begin{tabular}{cccc}
\hline Notch Frequency $\mathbf{( G H z )}$ & 3 dB Bandwidth $\mathbf{( G H z )}$ & Fractional Bandwidths (FBW) \% & Rejection Level (dB) \\
\hline 3.5 & 1.07 & 15.62 & 28.6 \\
7.5 & 0.61 & 8.91 & 25.1 \\
\hline
\end{tabular}

Table 4. Measurement results of the dual notched bands.

\begin{tabular}{cccc}
\hline Notch Frequency (GHz) & 3 dB Bandwidth (GHz) & Fractional Bandwidths (FBW) \% & Rejection Level (dB) \\
\hline 3.5 & 1.09 & 15.91 & 25.2 \\
7.5 & 0.66 & 9.63 & 17.3 \\
\hline
\end{tabular}


Figure 8a shows the examination photo of the fabricated filter by Vector Network Analyzer Plannar 804/1 (Copper Mountain Technologies, Indianapolis, IN, USA) with the frequency range of $8 \mathrm{GHz}$. The simulation data and the measured data are imported into the Excel form, and the comparison between the simulation results and the measured results is drawn by Origin software (OriginLab Corporation, Northampton, MA, USA) as shown in Figure 8b. According to Figure 8b, the measured insertion loss is lower than $1.2 \mathrm{~dB}$ and the reflection coefficient is higher than $15 \mathrm{~dB}$ over the ultra-wideband passband. The measured and simulation results have the same resonant frequencies. The equivalent model of resonant elements composed of the T-shaped resonator and L-shaped defect microstrip structure is proven to be correct by the consistent resonant frequencies.

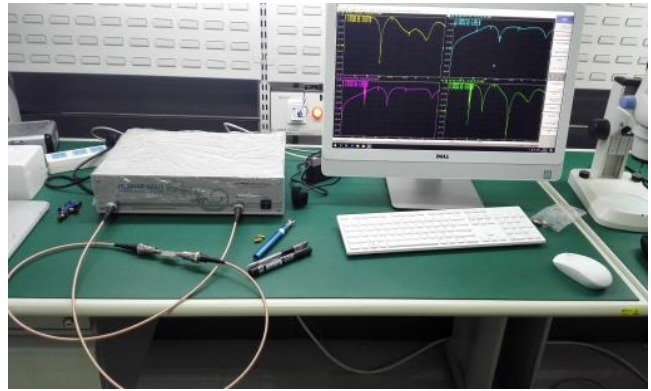

(a)

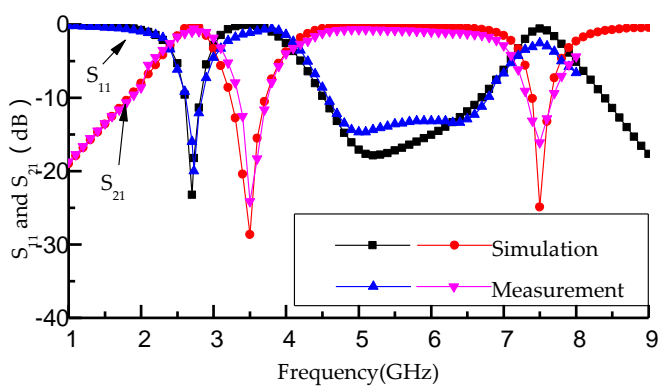

(b)

Figure 8. (a) The examination photo by Vector Network Analyzer Plannar 804/1 (Copper Mountain Technologies, Indianapolis, IN, USA); (b) comparison of the simulation and measurement results of the proposed filter.

Figure 9 illustrates the proposed filter performance with different parameters $\left(g_{1}, L_{6}, W_{6}\right)$ of the T-shaped resonator. Figure 9a depicts that the proposed filter performance is adjusted by changing L6 of the T-shaped resonator under the condition of $L_{6}=2 L_{5}$. As $L_{6}$ increases from 9.4 to $10.6 \mathrm{~mm}, f_{01}$ decreases from 4 to $3.5 \mathrm{GHz}$, while $f_{02}$ is still $7.5 \mathrm{GHz}$. It can be derived from the Equations (4) and (5) that this leads to the decreasing of $f_{01}$. Figure $9 \mathrm{~b}$ describes the proposed filter performance changing with different $\mathrm{W}_{6}$ of the T-shaped resonator when $L_{7}=11 \mathrm{~mm}$. It can be clearly seen that when $W_{6}$ increases from 0.4 to $0.6 \mathrm{~mm}, f_{01}$ increases from 3.4 to $3.6 \mathrm{GHz}$, while $f_{02}$ is $7.5 \mathrm{GHz}$. The FBW of the first notched band decreases from 16 to $14.8 \%$ and the FBW of the second notched band increases from $11.24 \%$ to $10.9 \%$.

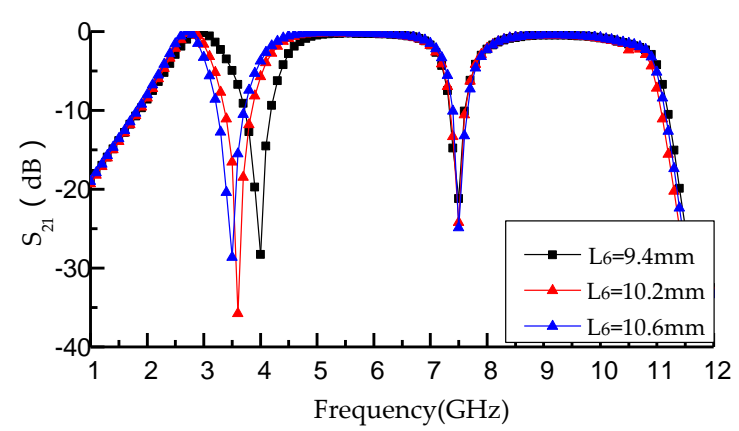

(a)

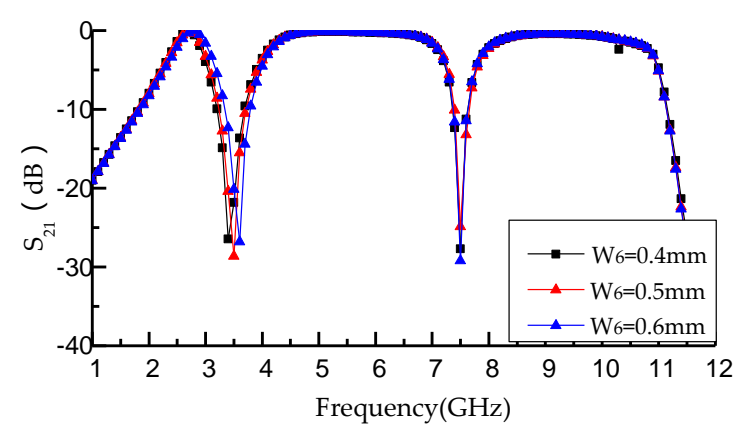

(b)

Figure 9. (a) Simulation results with different $L_{6}\left(L_{6}=9.4 \mathrm{~mm}, f_{01}=4 \mathrm{GHz}, L_{6}=10.2 \mathrm{~mm}\right.$, $\left.f_{01}=3.6 \mathrm{GHz}, L_{6}=10.6 \mathrm{~mm}, f_{01}=3.5 \mathrm{GHz}\right) ;(\mathbf{b})$ Simulation results with different $W_{6}\left(W_{6}=0.4 \mathrm{~mm}\right.$, $\left.f_{01}=3.4 \mathrm{GHz}, W_{6}=0.5 \mathrm{~mm}, f_{01}=3.5 \mathrm{GHz}, W_{6}=0.6 \mathrm{~mm}, f_{01}=3.6 \mathrm{GHz}\right)$.

Figure 10 respectively illustrates that the performance of the second notched band is adjusted by changing the relevant parameters $\left(L_{7}, L_{8}, W_{7}\right)$ of the L-shaped defect microstrip structure. The total 
length of the defect microstrip structure is equal to $L_{7}+L_{8}$ and the width is $W_{7}$. Figure 10a describes the proposed filter performance with changing $L_{7}$ of the L-shaped defect microstrip structure. When $L_{7}$ increases from 7.5 to $9.3 \mathrm{~mm}, f_{02}$ decreases from 7.7 to $6.2 \mathrm{GHz}$, while $f_{01}$ is $3.5 \mathrm{GHz}$. Figure $10 \mathrm{~b}$ shows the simulated insertion loss only with different $L_{8}$. When $L_{8}$ increased from 0.1 to $0.3 \mathrm{~mm}, f_{01}$ is $3.5 \mathrm{GHz}$ but $f_{02}$ decreases from 7.2 to $7 \mathrm{GHz}$. It can be derived from the equivalent equation of resonant elements that the $C_{2}$ of the equivalent circuit increases with the increasing of the total length of the L-shaped defect microstrip structure $\left(L_{7}+L_{8}\right)$. Figure 10c illustrates the proposed filter performance with different $W_{7}$ of the L-shaped defect microstrip structure. When $W_{7}$ increases from 0.2 to $0.4 \mathrm{~mm}$, $f_{01}$ and $f_{02}$ are maintained at $3.5 \mathrm{GHz}$ and $7.2 \mathrm{GHz}$. It can be clearly seen that when $W_{7}$ increases from 0.2 to $0.4 \mathrm{~mm}$, the FBW of the second notched band increases from $15.71 \%$ to $22.68 \%$. The resonant frequency $f$ of the L-shaped defect microstrip structure decreases with the increasing of the total length of the L-shaped defect microstrip structure $\left(L_{7}+L_{8}\right)$ as shown in Equation (10).

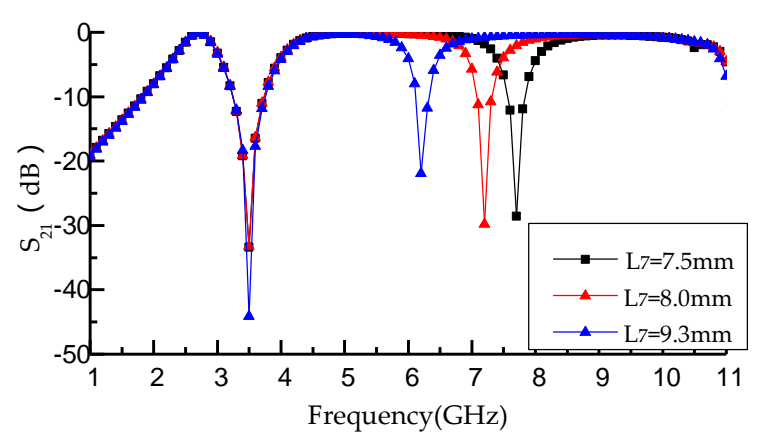

(a)

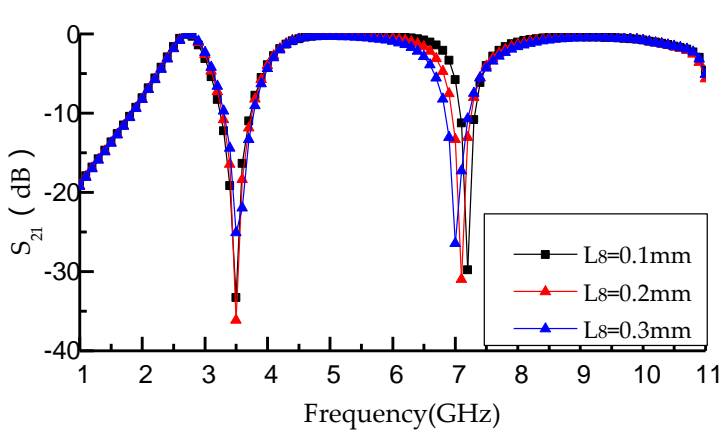

(b)

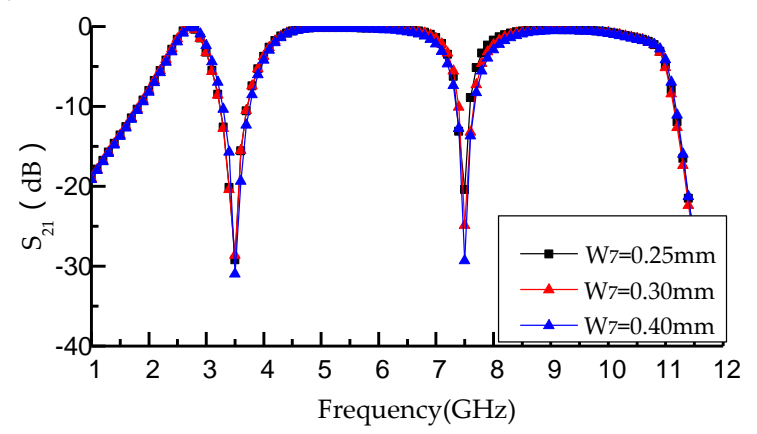

(c)

Figure 10. (a) Simulation results with different $L_{7}\left(L_{7}=7.5 \mathrm{~mm}, f_{02}=7.7 \mathrm{GHz}, L_{7}=8 \mathrm{~mm}, f_{02}=7.2 \mathrm{GHz}\right.$, $\left.L_{7}=9.3 \mathrm{~mm}, f_{02}=6.2 \mathrm{GHz}\right) ;(\mathbf{b})$ simulation results with different $L_{8}\left(L_{8}=0.1 \mathrm{~mm}, f_{02}=7.2 \mathrm{GHz}\right.$, $L_{8}=0.2 \mathrm{~mm}, f_{02}=7.1 \mathrm{GHz}, L_{8}=0.3 \mathrm{~mm}, f_{02}=7 \mathrm{GHz}$ ); (c) simulation results with different $W_{7}$ $\left(W_{7}=0.2 \mathrm{~mm}, W_{7}=0.3 \mathrm{~mm}, W_{7}=0.4 \mathrm{~mm}, f_{01}=3.5 \mathrm{GHz}, f_{02}=7.2 \mathrm{GHz}\right)$.

According to the above analysis, the frequency of the second notched band decreases by increasing the total length of the L-Shaped defect microstrip structure $\left(L_{7}+L_{8}\right)$ and the fractional bandwidths of the second notched band increases with the increasing of $W_{7}$, while the frequency of the first notched band is still at $3.5 \mathrm{GHz}$.

Finally, a comparison of characteristics between the proposed filter and some other filters is presented in Table 5, in which insertion loss and return loss are over the whole pass-bands, while $f_{\mathrm{L}}$ and $f_{\mathrm{H}}$ means the central frequency of lower and higher frequency notched bands. It can be seen that the proposed filter has dual notched bands at 3.5 and $7.5 \mathrm{GHz}$ with the rejection level of $25.2 \mathrm{~dB}$ and $17.3 \mathrm{~dB}$ and an FBW $123.9 \%$ higher than the other 10 works [22-31]. The measured results illustrate that the dual notched bands are centered at 3.5 and $7.5 \mathrm{GHz}$ with an FBW of $15.91 \%$ and $9.63 \%$. 
Table 5. Comparison of the proposed filter with recently proposed ultra-wideband bandpass filters with notched bands.

\begin{tabular}{cccccc}
\hline Ref. & Insertion Loss (dB) & Return Loss $(\mathbf{d B})$ & $f_{L}(\mathbf{G H z})$ & $f_{H}(\mathrm{GHz})$ & $\begin{array}{c}\text { Fractional } \\
\text { Bandwidths (FBW) \% }\end{array}$ \\
\hline$[22]$ & 0.5 & 13 & 5.5 & 13.6 & 112 \\
{$[23]$} & 0.6 & 12 & 6.55 & 8.66 & 130 \\
{$[24]$} & 0.65 & 10 & 4.9 & 8.5 & 110 \\
{$[25]$} & 1.2 & 11 & 4.3 & 9.1 & 82.4 \\
{$[26]$} & 1.1 & 10 & 2.4 & 5.5 & 110 \\
{$[27]$} & 1.5 & 15 & 2.4 & 5.2 & 105 \\
{$[28]$} & 0.7 & 15 & 1.16 & 3.5 & 105 \\
{$[29]$} & 1.1 & 15 & 2.62 & 5.32 & 92 \\
{$[30]$} & 2 & 11 & 5.8 & 8 & 89.6 \\
{$[31]$} & 1.12 & 15.5 & 2.4 & 5.2 & 123.9 \\
\hline
\end{tabular}

\section{Conclusions}

In this paper, a UWB bandpass filter with dual notched bands using a T-shaped resonator and L-shaped defect microstrip structure is designed and fabricated. The proposed filter has dual adjustable notched bands which are implemented by changing the parameters of the L-shaped defect microstrip structure and T-shaped resonator respectively. As the two simulation results obtained by using ADS and HFSS are consistent, the correctness of the equivalent lumped circuit composed of a T-shaped resonator and L-shaped defect microstrip structure is further verified. The proposed filter can suppress dispensable bands at $3.5 \mathrm{GHz}$ and $7.5 \mathrm{GHz}$, which can be designed and applied to the wireless communication system at WiMAX band and X-band by adjusting the parameters of the T-shaped resonator and L-shaped defect microstrip structure.

Author Contributions: X.Z. and T.J. conceived and designed the experiments; Y.P. tested the performance of the antenna and collected the measured data; X.Z. and T.J. analyzed the data; X.Z. wrote the paper.

Acknowledgments: This paper is funded by the International Exchange Program of Harbin Engineering University for Innovation-oriented Talents Cultivation. This work was partially supported by the National Key Research and Development Program of China (2016YFE0111100), Key Research and Development Program of Heilongjiang (GX17A016), the Science and Technology innovative Talents Foundation of Harbin (2016RAXXJ044), the Natural Science Foundation of Beijing (4182077) and China Postdoctoral Science Foundation (2017M620918).

Conflicts of Interest: The authors declare no conflict of interest. The founding sponsors had no role in the design of the study; in the collection, analyses, or interpretation of data; in the writing of the manuscript, and in the decision to publish the results.

\section{References}

1. Federal Communications Commission. Revision of Part 15 of the Commission's Rules Regarding Ultra-Wideband Transmission Systems; First Note and Order Federal Communications Commission, ET-Docket 98-153; Federal Communications Commission: Washington, DC, USA, 2002.

2. Wei, F.; Li, W.T.; Shi, X.W.; Huang, Q.L. Compact UWB bandpass filter with triple-notched bands using triple-mode stepped impedance resonator. IEEE Microw. Wirel. Compon. Lett. 2012, 22, 512-514. [CrossRef]

3. Wei, F.; Qin, P.-Y.; Guo, Y.J.; Shi, X.-W. Design of multi-band bandpass filters based on stub loaded stepped-impedance resonator with defected microstrip structure. IET Microw. Antennas Propag. 2016, 10, 230-236. [CrossRef]

4. Lu, X.; Wei, B.; Xu, Z.; Cao, B.; Zhang, X.; Wang, R.; Song, F. Superconducting ultra-wideband (UWB) bandpass filter design based on quintuple/quadruple/triple-mode resonator. IEEE Trans. Microw. Theory Tech. 2015, 63, 1281-1293. [CrossRef]

5. Wei, F.; Wu, Q.Y.; Shi, X.W.; Chen, L. Compact UWB bandpass filter with dual notched bands based on SCRLH resonator. IEEE Microw. Wirel. Compon. Lett. 2011, 21, 28-30. [CrossRef] 
6. Zheng, X.; Liu, W.; Zhang, X.; Jiang, T. Design of dual band-notch UWB bandpass filter based on T-shaped resonator. In Proceedings of the 2016 Progress in Electromagnetic Research Symposium (PIERS), Shanghai, China, 8-11 August 2016; pp. 4482-4486.

7. Zheng, X.; Jiang, T. Realization of Dual Notch Bands in UWB Bandpass Filter Using Two T-shaped Resonators. In Proceedings of the 2017 International Applied Computational Electromagnetics Society Symposium, Florence, Italy, 26-30 March 2017. [CrossRef]

8. Zhao, J.; Wang, J.; Zhang, G.; Li, J.-L. Compact microstrip UWB bandpass filter with dual notched bands using E-shaped resonator. IEEE Microw. Wirel. Compon. Lett. 2013, 23, 638-640. [CrossRef]

9. Zheng, X.; Jiang, T. Design of UWB bandpass filter with dual notched bands using E-shaped resonator. In Proceedings of the IEEE/ACES International Conference on Wireless Information Technology and Systems, Honolulu, HI, USA, 13-18 March 2016; pp. 1-2. [CrossRef]

10. Zhang, C.; Zhang, J.; Li, L. Triple band-notched UWB antenna based on SIR-DGS and fork-shaped stubs. Electron. Lett. 2014, 50, 67-69. [CrossRef]

11. Zhou, L.-H.; Ma, Y.; Shi, J.; Chen, J.; Che, W. Differential dual-band bandpass filter with tunable lower band using embedded DGS unit for common-mode suppression. IEEE Trans. Microw. Theory Tech. 2016, 64, 4183-4191. [CrossRef]

12. Zakaria, Z.; Mutalib, M.A.; Ismail, A.; Isa, M.S.M.; Ismail, M.M.; Latiff, A.A.; Zainuddin, N.A.; Sam, W.Y. Compact structure of band-pass filter integrated with Defected Microstrip Structure (DMS) for wideband applications. In Proceedings of the European Conference on Antennas and Propagation, The Hague, The Netherlands, 6-11 April 2014; Volume 21, pp. 2158-2162.

13. Wang, J.; Zhao, J.; Li, J.L. Compact UWB bandpass filter with triple notched bands using parallel U-shaped defected microstrip structure. Electron. Lett. 2014, 50, 89-91. [CrossRef]

14. Yao, B.; Zhou, Y.; Cao, Q. A UWB bandpass filter with multi notched bands using microstrip/coplanar waveguide. In Proceedings of the International Symposium on Antennas, Propagation and EM Theory, Kunming, China, 2-5 November 2008; pp. 637-640.

15. Mao, S.G.; Chueh, Y.Z.; Chen, C.H.; Hsieh, M.C. Compact ultra-wideband conductor-backed coplanar waveguide bandpass filter with a dual band-notched response. IEEE Microw. Wirel. Compon. Lett. 2009, 19, 149-151. [CrossRef]

16. Honarvar, M.A.; Sadeghzadeh, R.A. Design of coplanar waveguide ultrawideband bandpass filter using stub-loaded resonator with notched band. Microw. Opt. Technol. Lett. 2012, 54, 2056-2061. [CrossRef]

17. Senior, D.E.; Cheng, X.; Yong, K.Y. Dual-band filters using complementary split-ring resonator and capacitive loaded half-mode substrate-integrated-waveguide. In Proceedings of the Antennas and Propagation Society International Symposium, Chicago, IL, USA, 8-14 July 2012; pp. 1-2.

18. Pandey, A.K.; Chauhan, R.K. Miniaturized dual-band BPF for WiMax/WLAN applications. In Proceedings of the IEEE International Conference on Power Electronics, Intelligent Control and Energy Systems, Delhi, India, 4-6 July 2016; pp. 1-4.

19. Hong, J.S.; Karyamapudi, B.M. A general circuit model for defected ground structures in planar transmission lines. Frequenz 2015, 15, 706-708. [CrossRef]

20. Wang, J.; Ning, H.; Xiong, Q.; Li, M.; Mao, L.F. A novel miniaturized dual-band bandstop filter using dual-plane defected structures. Prog. Electromagn. Res. 2013, 134, 397-417. [CrossRef]

21. Gupta, K.C.; Garg, R.; Bahl, I.; Bhartia, P. Microstrip Lines and Slotlines, 2nd ed.; Artech House: Norwood, MA, USA, 1996.

22. Wang, K.; Wong, S.W.; Chu, Q.X. A compact UWB CPW bandpass filter with short-ended H-shaped resonator and controllable notched band. Microw. Opt. Technol. Lett. 2013, 55, 1577-1581. [CrossRef]

23. Nosrati, M.; Daneshmand, M. Compact microstrip ultra-wideband double/single notch-band band-pass filter based on wave's cancellation theory. Microw. Antennas Propag. Lett. 2012, 6, 862-868. [CrossRef]

24. Song, K.; Xue, Q. Asymmetric dual-line coupling structure for multiple-notch implementation in UWB bandpass filters. Electron. Lett. 2010, 46, 1388-1390. [CrossRef]

25. Wang, H.; Tam, K.W.; Ho, S.K.; Kang, W.; Wu, W. Design of ultra-wideband bandpass filters with fixed and reconfigurable notch bands using terminated cross-shaped resonators. IEEE Trans. Microw. Theory Tech. 2014, 62, 252-265. [CrossRef] 
26. Lung, C.K.; Chin, K.S.; Fu, J.S. Tri-section stepped-impedance resonators for design of dual-band bandstop filter. In Proceedings of the European Microwave Conference, Rome, Italy, 29 September-1 October 2009; pp. 771-774.

27. Chen, F.C.; Qiu, J.M.; Chu, Q.-X. Dual-band bandstop filter using stub-loaded resonators with sharp rejection characteristic. Electron. Lett. 2013, 49, 351-352. [CrossRef]

28. Gao, L.; Cai, S.W.; Zhang, X.Y.; Xue, Q. Dual-band bandstop filter using open and short stub-loaded resonators. In Proceedings of the International Conference on Microwave and Millimeter Wave Technology, Shenzhen, China, 5-8 May 2012; Volume 4, pp. 1-3.

29. Feng, W.J.; Che, W.Q.; Shi, S.Y.; Xue, Q. Compact dual-wideband bandstop filters based on open-coupled lines and transversal signal-interaction concepts. IET Microw. Antennas Propag. 2013, 7, 92-97. [CrossRef]

30. Peng, H.; Luo, Y.; Zhao, J. Compact microstrip UWB bandpass filter with two band-notches for UWB applications. Prog. Electromagn. Res. Lett. 2014, 45, 25-30. [CrossRef]

31. Tilanthe, P.; Sharma, P.C.; Bandopadhyay, T.K. A monopole microstrip antenna with enhanced dual band rejection for UWB applications. Prog. Electromagn. Res. B 2012, 38, 315-331. [CrossRef]

(C) 2018 by the authors. Licensee MDPI, Basel, Switzerland. This article is an open access article distributed under the terms and conditions of the Creative Commons Attribution (CC BY) license (http://creativecommons.org/licenses/by/4.0/). 